\title{
Study on Governance of Coalmine Accidents of China from the Perspective of Public Administration
}

\author{
Han Quanfang ${ }^{1,2}$ Ge Shaolin ${ }^{2}$ \\ ${ }^{1}$ Institute of Sociology Chinese Academy of Social Sciences, Beijing, P.R.China, 100732 \\ ${ }^{2}$ School of Public Management, Yunnan University of Economics and Finance, Kunming, P.R.China, \\ 650221 \\ (1.hqfang666@163.com; 2.geshaolin72@yahoo.com.cn)
}

\begin{abstract}
The coalmine accidents has become one of the hotpoints in China, which now absolutely has already turned to be a key issue related to the healthy development of economic and social harmony. This article based on government regulation, government failure, public policy and public management theory and reviewed the research from the government, legal, economic and corporate and etc., analysis the mine death toll of Sino- American and the death rate per million tons of coal of 2000-2010 in China comprehensively as well as the deep-seated reasons of forming such mine accidents. Based on public Administration, countermeasures and suggestions of solving the above problems has been come up with.
\end{abstract}

Keywords: Coalmine Accidents, Public Administration, Governance, the Death Rate per Million Tons of Coal

\section{Introduction}

Coalmine accident refers to disasters which happened in mine. Common mine accidents include gas explosion, dust explosion, gas outburst, flooding accident, mine fire, mine roof collapse and etc. China mine problem is a prominent hot issue, which is the key problem related to economic and social healthy development and social harmony. The coalmine accidents usually cause devastation and serious threat to miners' lives and safety. In recent years, the press about mine accident has become one of the hot news in China. For example, gas explosion in Sunjiawan, Liaoning occurred on February 14, 2005 caused 214 people dead; Hongtong, Shanxi coal mine gas explosion occurred in December 5, 2007 ,105 people were killed; Hegang Fuhua ,Heilongjiang coalmine accidents caused 31 people being killed,
September 20, 2008. September 8, 2009, Henan Pingdingshan mine caused the death of 79 people. Linfen, Shanxi flooded coal mine flooding accident March 28, 201038 people died; November 10, 2011, Yunnan the Shizong mine, 35 people were killed and eight were missing; November 24, 2012, Guizhou Xiangshui mine 23 people were killed in a mine incident. [1] This article deeply analysis the status quo of Chinese mine and the causes of mine disaster based on the theory of government regulation, government failure, public policy , and put forward countermeasures and suggestions of mine governance from the perspective of Public Administration. 


\section{Coalmine Accidents Research Summarize}

From foreign study, the United States, Australia and other coal-producing country has basically eliminated the major coalmine accidents, the coal mining industry is quite safe. So there is little foreign literature on mine. China mine accidents is frequent, catastrophe losses and enormous impact is huge, the government and the people are highly concerned about mine accidents. Chinese scholars for mine research are focused on the analysis of the causes of the mine, coalmine accidents prevention countermeasures, as well as governance mine measures.

From the government perspective, some people like Peng Xiaoya believe that the political root causes of the coalmine accidents is the seriously "official coal collusion”. [2] Li Lihong, Wang Jingyu think it's necessary to establish an effective supervision and restraint mechanisms, and to crack down on social vices of "official coal combined, the official coal become one" ,to establish, improve and implement the government emergency response mechanism to deal with public sudden crises, to minimize the hazards of mining accidents. [3] Zhao Zengxing insists that mine accidents is a reflection of lacking government responsibility, imperfect government management system, and low sense of responsibility. He also put up the deep-seated causes of the frequent mining accidents is the absence of Government and Government offside. Only if strengthen government responsibility, improve corporate responsibility awareness, will the coalmine accidents momentum get effective containment, the security of life and property of the people get reliable protection. [4] Cheng Xumin thinks that the failure of the government and its security management departments in the coal mine safety management [5] is an important reason for Chinese coal mine safety accidents. Liu Fagen proposes to strengthen the safety management, implement coal mine safety production responsibility system, speed up the mine safety work pattern of sound national monitoring, local regulatory and enterprise responsibility. [6]

From a legal perspective, the Chinese national security production theory expert group members Professor Luo Yun pointed out that the causes of mine accidents is very complex, but it boils down to a key point is that the laws and regulations did not really put in place. Li Yehong believes inadequate legislation and lax enforcement is the important causes of the coalmine accidents. Further improvement of legislation, strengthen the application of the law, as well as raise awareness of the law is needed to curb the occurrence of coalmine accidents. [7] Yang Jun thinks the lack of scientific, systematic, which leads to the legal system lose its effectiveness is one of the root causes of the coalmine accidents. He pointed out that the biggest drawbacks of the state ownership of mineral resources is the legal face two problems: First, the ownership of the main body absence; Second, the responsibility of the main body fuzzy. Such a system can easily lead to a lot of waste of resources, inadequate safety production inputs, corruption, and serious environmental pollution, as well as mine public tragedy. [8] Li Ning proposes to improve relevant laws and regulations to prevent the coalmine accidents. [9]

From an economic perspective, Peng Xiaoya believes the vague of mineral resource property rights on the one hand lead to corruption and rent-seeking behavior, on the other hand, lead to predatory exploitation of mineral resources and wasted, which is the economic roots of the mine disaster occurred. [2] Tu Jin insists that Chinese social reform is not complete, the market economy is still not perfect, government and citizen interaction is relatively weak, government management also has a number of institutional obstacles, which is the origin of the coalmine accidents occurred. 
[10] Li Lihong thinks that property rights in the area of coal mining must be clear and the reform of property rights is necessary to ensure the stability of the coal mine owners operating; government should regulate the exploitation of mineral resources market, the state reasonably regulate and control the supply and demand of important resource; using economic instruments to economically penalize the violation of coal mine product regulation. [3]

From the enterprise level, Zhao Zengxing believes that mine accidents is largely related to light corporate responsibility .When enterprises illegal benefits far outweigh the cost of illegal businesses, they will not be afraid of risk and dare to try. [4] Cheng Xumin considers that mine safety accidents occur frequently, the largest main body of responsibility is the coal enterprises. [5] Liu Fagen thinks that coal mining enterprises seriously lack technical personnel workers' low safe quality is one of the reasons of the coalmine accidents occurred. [6] Li Ning believes that coalmine accidents occurred is due to super strength exploitation, super power production and weak management. [9]

\section{Status of Chinese Coalmine Accidents}

\subsection{Coalmine Accidents Death Toll Base}

Huge
The coal industry is an important energy basic industry, and the pillar industry in Chinese economic construction and social development, but the coal industry is also one of the accident-prone industry. Since 2001, the State Council set up the State Administration of Work Safety, authoritative information data show that Chinese coal mine accident deaths in the 2002 peak, has for nine consecutive years of decline, from 2002 to 2011, coal mine accidents in total number and the absolute number of deaths is declining, coal mine accident deaths by 6995 people in 2002 down to 2011, 1973 people, among which the death toll of coal mine accidents in 2009 to 2631, the death toll of coalmine accidents in 2010 to 2433 (Figure 1). The year of 2011 is the best situation of coal mine safety production in recent years, the annual coalmine accident deaths in 1973, year-on-year down 460, decline 18.9\%, dropped to below 2,000 for the first time, to achieve a historic breakthrough. Mine experts said that mine death toll low is China is initially apparent of promoting the role of the coal industry restructuring, and we should also see the entire production safety situation is still grim. Statistics show that $70 \%$ of the coal mine deaths are concentrated in $15 \%$ the coal mines, if it continues to carry out regulation, mine death toll will further reduce.

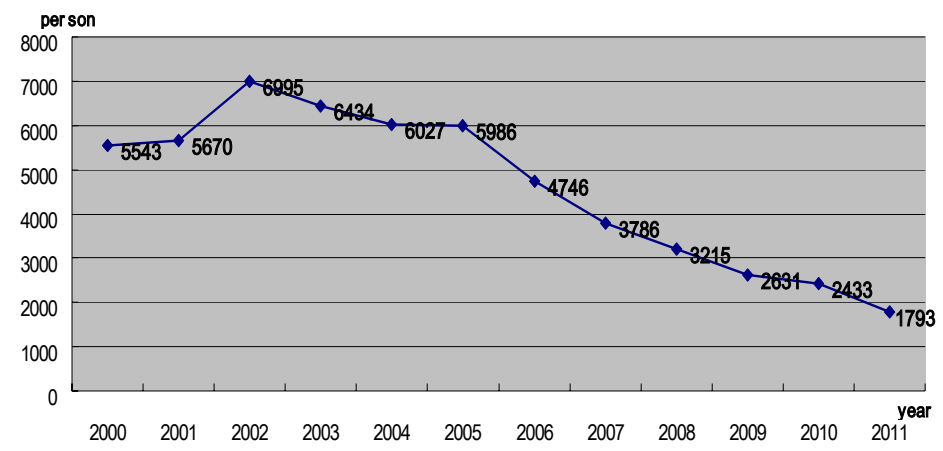

Figure 1: The death toll of coalmine accidents of China from 2000-2011

Source: State Production Safety Supervision Administration of websites and media publicly reported data management over the years 
In 2011, from the situation of the region, Gui Zhou, Hu Nan, Si Chuan, Yun Nan, Chong Qing still the hardest hit area of coal mine accidents, the five areas of the national coal mine accident death over one hundred, Gui Zhou reached 279, Hu Nan Sichuan were 251 people, 240 people, above-mentioned five regional coal mine deaths accounted for more than half of the national death toll in such accidents. Shanxi, Shaanxi and Inner Mongolia, the main producing areas of the national coal, no major accidents occurred in 2011. Among them, the actual number of deaths for the full year coal mine accident in Shanxi Province is 74; Shaanxi Province for seven consecutive years, dropped significantly Annual coal mine accident death toll to 73 people; Inner Mongolia region's annual coal mine accident death toll to 50. Control objectives to see from the whole year, among 25 regions of coal mine accidents occurred, 21 completed the year control indicators. And Inner Mongolia, Yunnan's both annual coal mine deaths and the large occurrence of coalmine accidents are more than the annual control indicators. [11] The reduce of coal mine accident death toll was initially apparent promoting the role of the coal industry restructuring, reduce the number of small coalmines which production conditions is not up to standard. It's a correct choice to improve production efficiency, and control the trend of high incidence of coal mine accidents.

\subsection{The Death Rate per Million tons of Coal is High}

Chinese coal output ranks first in the world, accounting for about $39 \%$ of the world, but the mine deaths accounted for $80 \%$ of global mine death which is about 70 times of the United States, 17 times of South Africa, 10 times of Poland, 7 times of Russia and India. [6]The miners always among the top 10 dangerous occupations in the Chinese media published. Compared with the United States, according to official statistics, in 2003 the absolute annual output of coal in China and the United States or less, about 12 million tons, the United States is about 10 million tons. But Chinese coal mine accident deaths and one million tons mortality were much higher than that of the United States. Chinese coal mine accident deaths for 6342, the death rate per million tons of coal was 4.17, U.S. coalmine accidents death toll to 30 million tons of coal mortality rate of 0.029 .

\begin{tabular}{|c|c|c|c|c|}
\hline \multirow{2}{*}{ year } & \multicolumn{2}{|c|}{ China } & \multicolumn{2}{|c|}{ America } \\
\cline { 2 - 5 } & $\begin{array}{c}\text { Death toll } \\
\text { (person) }\end{array}$ & $\begin{array}{l}\text { Death rate per million tons } \\
\text { of coal }\end{array}$ & $\begin{array}{c}\text { Death toll } \\
\text { (person) }\end{array}$ & $\begin{array}{c}\text { Death rate } \\
\text { Per million tons of coal }\end{array}$ \\
\hline 2000 & 5543 & 5.86 & 25 & 0.028 \\
\hline 2001 & 5670 & 5.2 & 23 & 0.027 \\
\hline 2002 & 6995 & 5.02 & 27 & 0.028 \\
\hline 2003 & 6434 & 4.17 & 30 & 0.029 \\
\hline 2004 & 6027 & 3.08 & 28 & 0.029 \\
\hline 2005 & 5986 & 2.84 & 22 & 0.027 \\
\hline 2006 & 4746 & 2.04 & 47 & 0.033 \\
\hline 2007 & 3786 & 1.485 & 37 & 0.03 \\
\hline 2008 & 3215 & 1.182 & 52 & 0.035 \\
\hline 2009 & 2631 & 0.892 & 34 & 0.03 \\
\hline 2010 & 2433 & 0.749 & 28 & 0.029 \\
\hline
\end{tabular}

Table 1 The Comparison of Death rate per million tons of coal between China and America from 2000-2010

Source: State Production Safety Supervision Administration of websites and media publicly reported data management over the years 


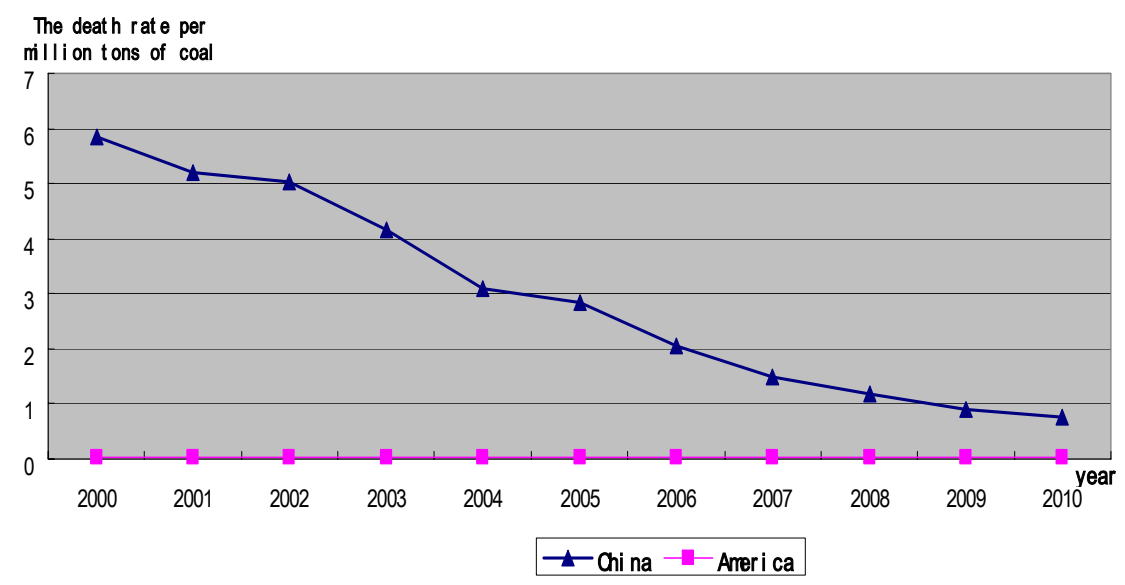

Figure 2 Comparison chart of Death rate per million tons of coal between China and the United States of America from 2000 to 2010

In 2010, Chinese coalmine accidents death toll for the first time dropped to less than 2500, the death rate per million tons of coal dropped to 0.749 .In 2011, the national coalmine accidents deaths dropped for the first time below 2,000 people, the death rate per million tons of coal dropped to 0.564.In 2012, four indicators of coal mine safety significantly decline, year-on-year decrease of 422 from the national coal mine accidents and deaths, 589 people, a decrease of $35.1 \%$ and $29.9 \%$ respectively; larger accidents and the death toll down to 14 and 61 people, respectively decreased $16.5 \%$ and $14.8 \%$; the number of deaths in serious accidents is down to 5 , and 77 people, respectively, a decrease of $23.8 \%$ and $22.0 \%$; The death rate per million tons of coal was 0.374 , down $33.7 \%$ year-on-year, for the first time fell to 0.5.

\section{Coalmine Accidents Causation Analysis}

The reasons for the formation of Chinese mine disaster is very complex, both natural factors, but more of a man-made factors. This article is primarily analyze a human factors of mine from the perspective of public administration. Since the 1970s, western social, economic and managerial crisis promoted the canonical form reform of public management and public administration research. Public governance theory does not require the government hands, the government should play the role of "The Night Watch" to do the things they should do and can do, do not force the top-down, hierarchical social order, and the emphasis on a range of theories of equal dialogue between the various organizations of system of cooperation in the network society. Mine regulation belongs to the part of the public administration, it should be stressed that the cooperation on the basis of market principles, the public interest and legitimacy agree. Specific operation process, the role of the Government is not rowing but at the helm, not to control but to coordinate. Analysis from the perspective of public administration, the main reasons for the formation of the Chinese mine following aspects.

\subsection{Security System is Imperfect}

Chinese coalmine safety system and institutions are not perfect, and the management and implementation of the security system is not in place. The main problem is that the "can not strict it up, the implementation does not go." In order to control the problem of coalmine production safety, SAWS issued a leader of coal mine go down into well and safety supervision and inspection requirements ", but encountered resistance in the real execution told us that to perfect the system designed to govern coal mine production safety. Still do not have the safety 
conditions in the mine, the communication between miners and safety supervision departments is difficult; official coal mine production the collusion phenomenon still rampant, so we need to strengthen the supervision and measures to ban or suspend production and management qualifications.

\subsection{Authority Rent-Seeking}

Government agencies have a high degree of monopoly regulation powers, is actually a scarce, exclusive assets. Such assets can bring high monopoly gains, in fact, constitute a rent. The activities carried out by the enterprise to obtain government regulation protection, known as rent-seeking behavior, so capital and power alliance formation. Government officials or state-owned enterprises became a shareholder in the small coal mines to seek illegal interests. Government officials secretly running the coalmine or The refuge relatives illegal mining operation, government officials in violation abuse the right of approval, and accepting the miners bribes, connivance, harboring coal mines illegal production and operation, participation or default cover up to conceal the accident.

\subsection{Weakening of Enterprise Security Management}

Less investment in enterprise security, some leader lack sense of responsibility to the staff and state property, look down upon safe production and look upon economic benefits is common. Management and accountability are not in place. Corporate safety culture is not perfect, the security system is imperfect. The punishment of the persons responsible for the accident is not adequate. Enterprise security management is the guarantee of the coal mine production safety production, therefore we must constantly improve and enhance the safety management and safety awareness.

\subsection{Safety Insufficient Capital Investment}

In recent years, due to the adjustment of the national industrial policy, the coalmine truly embark on a self-financing and self-development road. Due to the limitations of a variety of conditions, and the impact of a variety of reasons, resulting in low economic efficiency and a serious shortage of security funding is more prevalent. Some coal mining enterprises to reduce costs, some enterprises to streamline the organization cancel the original self-organized technical schools, workers can not carry out job training; Some corporate training workers a mere formality; some enterprises simply connected formal training, training of new entrants miners pushed down the mine. As most of the miners are not professionally trained, low quality of its own, there are many illegal operations phenomenon in the production process.

\section{Improve Chinese mine Governance Countermeasures}

First, strengthen the government management of the coalmine. The mineral resources belong to the state, either the mineral resources of the country on the surface or underground, can not be changed because of the attachment to the land ownership or the right to different use. State Council exercise ownership of mineral resources on behalf of the State . geology and mineral resources department of the State Council authorized by the State Council in charge of the national mineral resources allocation . Establish, improve and implement the government emergency response mechanism to deal with public sudden crises, to minimize the hazards of mining accidents.

Second, rent-seeking space compression between government officials and mine operators. In theory, the local government of the county and township is coal mine safety supervisor . However, due to the presence of the rent, rent-seeking by coal mine operators lead to the local government officials are operator at their own area .Increase penalties for undocumented coal mining enterprises, thereby 
reducing the total rental income of the coal mining enterprises, to reduce the possibility of them go to rent-seeking to government officials.

Third, to perfect the trigger mine legal construction. The legal level to improve the mineral rights mechanisms, rationalize the relationship between coal resources property rights law and regulatory law, the construction of full-time workers safety training mechanism, perfect miners interests relief system, reduce the rate of mine disaster occurred, realize the goal of the coal mine production safety.

Fourth, strengthen social supervision by public opinion forces. Rent-seeking behavior between the mine owners and local officials in part caused by the asymmetry of information between the parties and the public. Central government and local governments should establish a coal mine production safety problem reporting system and a variety of mechanisms, the positive incentive relevant informants or groups, to guide public opinion on coal mine production safety supervision, and reduce the central government and local governments, local governments and coal mining asymmetric information between the mine enterprise

Fifth, to build a reasonable mine compensation system. The establishment and improvement of third-party accident insurance compensation mechanism, increase the constraints on coal mining enterprises or mine safety investment, improve mine compensation payment. To expand the coal mine production safety expenses extraction system and production safety risk mortgage system, to increase economic incentives for coal mining enterprises or mine safety investment. To develop a reasonable safety standard, improve the efficiency of safety regulations. Fourth, from a legal point of view to protect the legitimate interests of the vulnerable groups

Sixth, strengthen the construction of coal unions. The reality of the large coal mine in China, a large number of groups of miners have not formed a powerful interests of the Commonwealth. Under the context of the labor oversupply , miners' choice of wages and safety often change into the choice of employment and unemployment. Therefore, to achieve the purpose of reducing the incidence of coalmine accidents, we need to strengthen the organization of the miners 'union building, improve miners' collective bargaining power of groups to protect their own interests and life safety of mine workers.

\section{Conclusions}

The coalmine accidents are the focus problem related to social harmony and stability, healthy economic development and people live and work. Coalmine accidents have become a serious social problem, it is not only related to the lives of the miners themselves, but also affect the daily lives of the miners' relatives, and affect the public's value judgments of the country assumed the protection of citizens. The face of the mine, we must make efforts to prevent mine frequently occurred. It has realistic significance to Improve safety and production work for the consolidation of social stability, economic construction of the country's stable political environment; It has an important role for balanced development of the various departments and for the protection of labor productivity in various sectors of economic and labor resources; It has real economic significance for society wealth and reduce economic losses ,for production staff relationship and personal security of life and health, family happiness and life quality. To ensure production safety is the requirements of the Constitution and the national nature, is the symbol of the social progress and civilization, is the important connotation based on people-oriented, is the cornerstone of national security and social public security, is the foundation and conditions of the productivity development, is the guarantee of the people to 
live and work in peace and contentment and the manifestation of the people's life quality.

\section{Acknowledgments:}

Fund: This article sported by China Postdoctoral Scientists Science Foundation(NO. 2012M510682). Ministry of Education, Humanities and Social Sciences Youth Fund(NO.12YJC840007).Ministry of Education, Humanities and Social Sciences western and Border areas Fund(NO.11XJA840002). Foundation of Yunnan University of Economics and Finance (NO.YC10D007).

\section{References}

[1] http://baike.baidu.com/view/185689.htm.

[2] Peng Xiaoya, Miu Yongzheng, Lu Xiaoyan. Causes and Countermeasures of frequent mine disasters in China[J]. Mining Technology,2008,8(5): 59-61. (In Chinese).

[3] Li Lihong, Wang Jingyu. Study on Coalmine accidents of effective mechanism of government governance [J].Chinese Public Administration, 2006, (9): 13. (In Chinese).

[4] Zhao Cenghang. The government responsibility from the frequent mining accidents[J].Legal System and Society, 2010, 2(5): 139. (In Chinese).

[5] Cheng Xumin. The Research Review of Causes and Countermeasures of the frequent mining accidents[J]. Shandong Coal Science and Technology, 2009, 3(4): 181.

(In Chinese).

[6] Liu Fagen, Xie Xing Kang . Analysis of mine accidents and Countermeasures [J].

Zhongzhou Coal, 2010, (3): 98-99.

(In Chinese).

[7] Li Hongye, HU lijian. The Reason and Solution of ChineseMine Tragedy [J]. The Reason and Solution of ChineseMine Tragedy, 2006, 22(5): 15-17. (In Chinese).
[8] Yang Jun. The origin and legal analysis of frequent mine disasters in China [J]. Administrative Tribune, 2009, 16(3): 44-47. (In Chinese).

[9] Li Ning. The Reasons that the Coal Mine Accidents Occurred Frequently and the Countermeasures to Solve [J]. Journal of Shanxi Politics and Law Institute for Administrators, 2007, 20(2): 78.

(In Chinese).

[10] Tu Jin. Political and economic analysis of mine disaster [J].Journal of Party College of Sichuan Province Committee of CCP, 2006, 6(2): 20. (In Chinese).

[11] State Administration of Work Safety[OL]. http://www.chinasafety.gov.cn/newpage/. 